\title{
RE-ORIENTING TRADITION - FASHIONING THE WARANGAL DHURRIES
}

\author{
DR. MALINI DIVAKALA ${ }^{1} \&$ JYOTHIRMAI SINGOTHU ${ }^{2}$

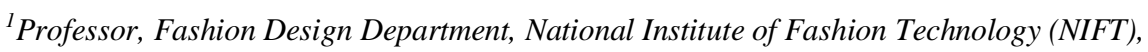 \\ Cyberabad, Madhapur, Telangana, India \\ ${ }^{2}$ Associate Professor, Textile Design Department, National Institute of Fashion Technology (NIFT), \\ Cyberabad, Madhapur, Telangana, India
}

ABSTRACT
The Indian weavers, dyers, printers, and embroiderers have mastered the art of indigenous play of their hands in
creating masterpieces of textile items. The craft of Dhurrie making in Warangal a town from Telangana state, India
is one such handwoven expertise that has gained significant relevance in the field of woven Indian traditions. The
study was formulated within an ethnographic framework coupled with an exploratory approach to explore the
possibility of the durrie being applied as an apparel fabric.
KEYWORDS: Dhurries of Warangal, Carpets, Rugs \& Dhurries for Apparel

Received: Jul 20, 2021; Accepted: Aug 10, 2021; Published: Aug 20, 2021; Paper Id: IJTFTDEC20214

\section{INTRODUCTION}

Indian textile crafts have carved a niche for their indigenous nature of the technique, pattern, and cultural significance. These indigenous craft traditions play an important role towards spurring thought and innovation in society. The crafts that have well flourished in the past, today struggle to remain relevant in the modern urban markets, necessitating changes in tune with the market scenarios. With a wide array of textile crafts, the Indian subcontinent has a recognizable contribution to the world textile trade from the $17^{\text {th }}$ century onwards. The Indian weavers, dyers, printers, and embroiderers have mastered the art of indigenous play of their hands in creating masterpieces of textile items. The craft of Dhurrie making is one such handwoven expertise that has gained significant relevance in the field of woven Indian traditions. Dhurries, an economical version of their counterpart, the carpets, are typically floor coverings and are described as flat-woven reversible rugs made of cotton in simple stripes, floral or geometric designs on a plain weave background (Levick, M. et. al., 2008).

Warangal city in Telangana state of South India is one of the important clusters for dhurrie weaving. Warangal dhurries were popular utility items and were used as a layer of bedding until a few decades ago. Over the years the Warangal Dhurrie remained versatile as a floor covering, and the weavers fostered the craft as a means of livelihood. Textile traditions possess potential towards progressive design interventions. Such strategies, aid in strengthening the cultural roots as new designs with urban connect generate a wide consumption audience propelling its market potential. It is easy for a traditional skill to be lost when the knowledge isn't passed on to the next generation. Design professionals have a challenging responsibility to keep the traditions and spirit of the craft alive. This paper showcases a progressive design strategy as it explores the possibility of re-orienting the dhurrie from a product of home fashion into an avenue for fashion apparel. 


\subsection{The Tradition of Dhurrie Making at Warangal}

Located in the South Indian state of Telangana (Picture 1). Warangal carpets are a pride of the region. Dating back to the Mughal era, the craft of weaving these floor coverings has been a means of basic livelihood for the locals here. A part of Nizam's Golkonda province until its capture by the Mughals in 1725, Warangal was a designated center for carpet weaving as a supplier of carpets and prayer mats to Muslim royalty. (Ranjan, A \& Ranjan, M. P. 2009) The abundant availability of cotton raw material may be the reason for it being housed within Warangal.

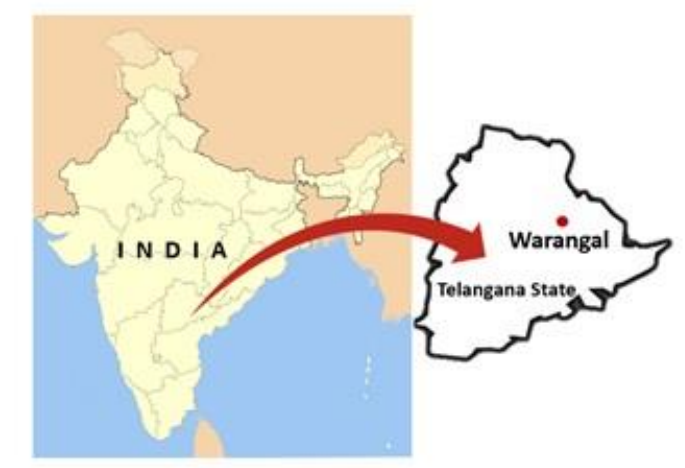

Picture1: Warangal, Telangana State, India.

The Great Exhibition of 1851 in London showcased two Warangal carpets woven in silk. They held a place of pride among over a lakh of exhibits, which included the fabled Koh-i-Noor diamond. Watt G (1903), describes that the Warangal carpets shown at this exhibition in 1851 may be said to have been both a surprise and revelation to many. The peculiarity of these rugs as described by Sir George Birdwood was that the exceedingly fine count of stitches, about 12000 to a square inch with perfect harmonious coloring, indicated the adeptness of the weaver and the prominence of the product.

Red and blues in combination with neutral colors, geometric, angular motifs woven in plain weave with a design range of flat weaves with raised or extra weft patterns using cotton and jute is the signature style of Dhurries of Warangal.

Warangal dhurries is an established industry in the Telangana state with a large community of skilled laborers and artisans for both dyeing of the yarn and weaving. There are typically 3 types or purposes of carpets that are made in Warangal

- Jainamaaz/ Musallah or a prayer rug used by the Muslim community

- Block printed carpets that are used as lifestyle products in home interiors

- Jamkhanas or Shathranjis, woven with geometrical patterns that are used during guests' arrivals at homes, marriages, and special ceremonies. (Picture 2) 


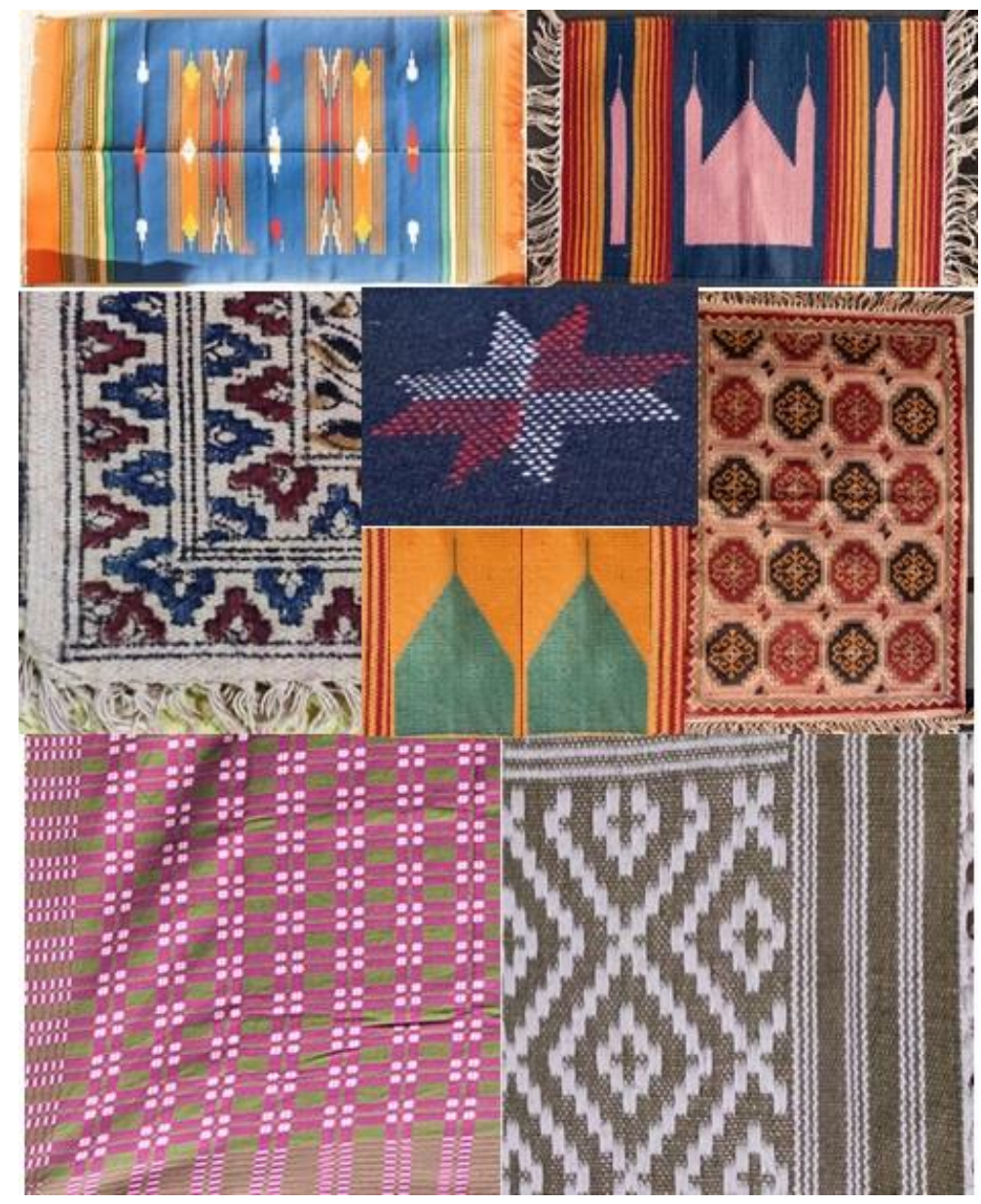

Picture 2: Warangal Dhurries Motifs and Designs.

\subsection{Process}

The process of weaving Dhurries at Warangal is carried out in two stages (Picture 3)

- Yarn dyeing

- Weaving

\subsubsection{Stage 1 Yarn Preparation and Dyeing}

These yarn-dyed bright-hued dhurries are typically made with cotton and jute. The yarns sourced from the local market are subjected to scouring to remove the dust and dirt followed by hank dyeing. The weavers are familiar with natural as well as chemical dyeing processes. Currently, Reactive dyes, Direct dyes, and Vat dyes are used for dyeing. Reactive dyes are more preferred due to their wide range of bright hues with good fastness qualities. Bright colors such as Greenish yellows, turquoise or greenish-blue, scarlets and reds, are generally in much demand.

\subsubsection{Stage 2: Weaving}

Similar to any handloom weaving process, Dhurrie weaving involves a 3 step procedure viz., Warping, Winding, and Weaving

1.2.2.1 Warping: Generally, warping for 3 Dhurries is done at a time. The type of end product dictates the usage of the 
warp and weft count. Dhurries with cotton or jute base utilized 2 to 5 ply yarn of coarse counts such as $6 \mathrm{~s}$, $10 \mathrm{~s}$, or 20 s for the warp.

1.2.2.2 Winding: The dyed hank for the weft is un-wound and wrapped around a round bamboo frame to be further transferred to a small iron rod called "Kande (Pirn rod)" with the help of charkha. These pirns carrying 2/ 2s or 6/6s count cotton yarn are used as weft in the shuttle for weaving.

1.2.2.3 Weaving: Weaving is carried on fly shuttle pit looms. Plain weave with weft interlock technique is practiced in the Warrangal dhurries. Jute yarn is used for the extra weft. Solids, yarn-dyed stripes, geometric and angular floral motifs are commonly observed in these Dhurries. Warangal dhurries often feature a combination of surface patterns such as yarn tie dye, lehariya, screen prints, or kalamkari block prints. Weaving techniques such as interlock and jacquard typically form the base
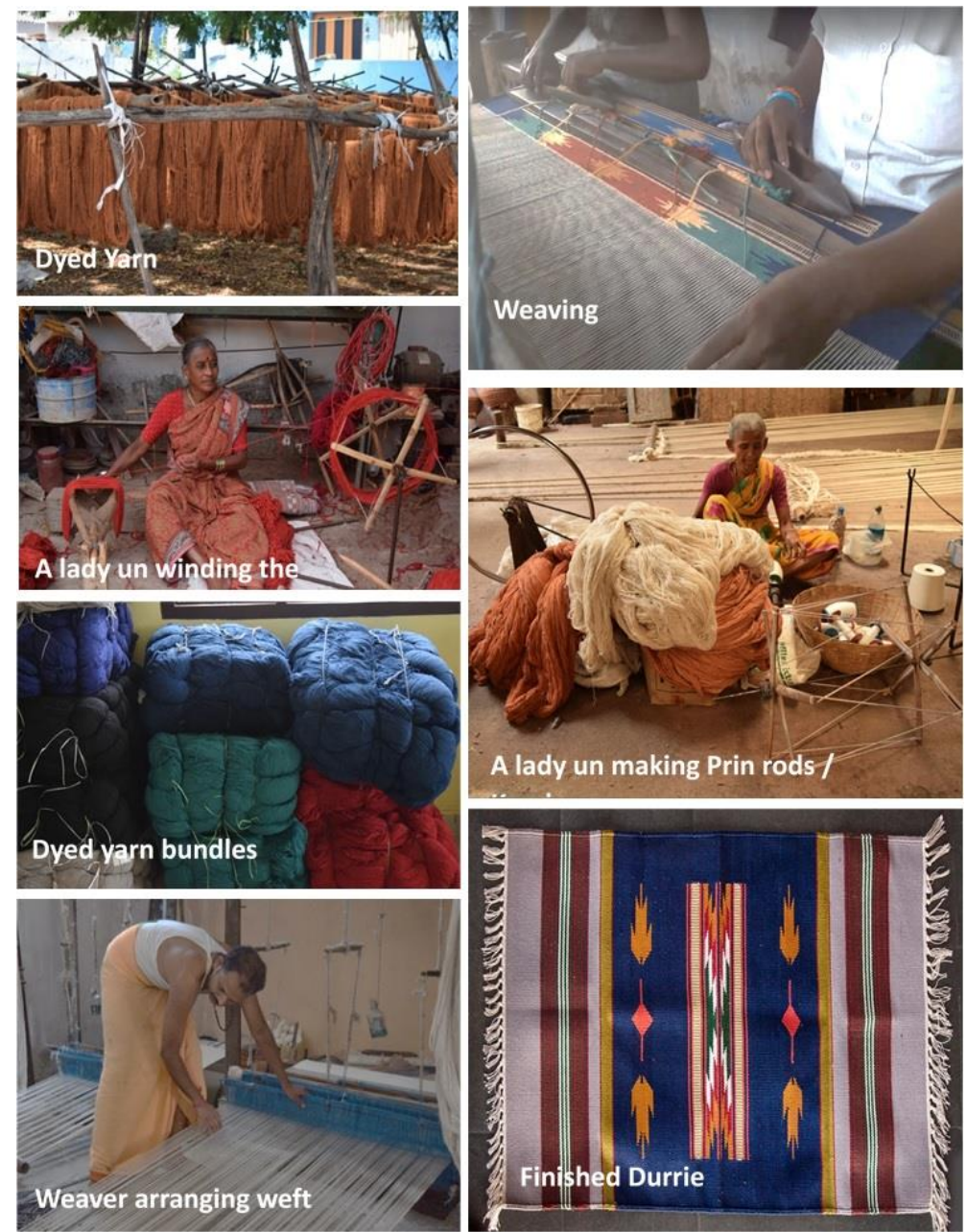

Picture 3: Making Process of Warangal Dhurries.

\section{METHODOLOGY}

The study was formulated within an ethnographic framework coupled with an exploratory approach. Fashion design students of NIFT Hyderabad explored the possibility of the Dhurrie being applied as an apparel fabric. Explorations related to alterations of yarn count have been carried. Further exploration within the thematic approach for an aesthetic balance has 
been carried out as per target clientele.

\subsection{Exploration 1: (Picture 4)}

\subsubsection{Aim}

Re-orient the dhurrie weave towards a women's outerwear apparel fabric

\subsubsection{Modifications Applied to the Yarn}

The regular cotton warp of $6 / 20$ s count yarn was altered to a $3 / 20$ s count. This ensured a reduction in the weight of the fabric and facilitated an improved drape that is suitable for outerwear apparel. Multicolored ply yarn was used to create a speckled surface with color.

\subsubsection{Modifications Applied to Color}

A color scheme based on a theme-based concept was developed in accordance with the forecasted trends for A/W 2019-20

\subsubsection{Washing}

The fabric was given a softening silicon wash to improve the hand and drape.

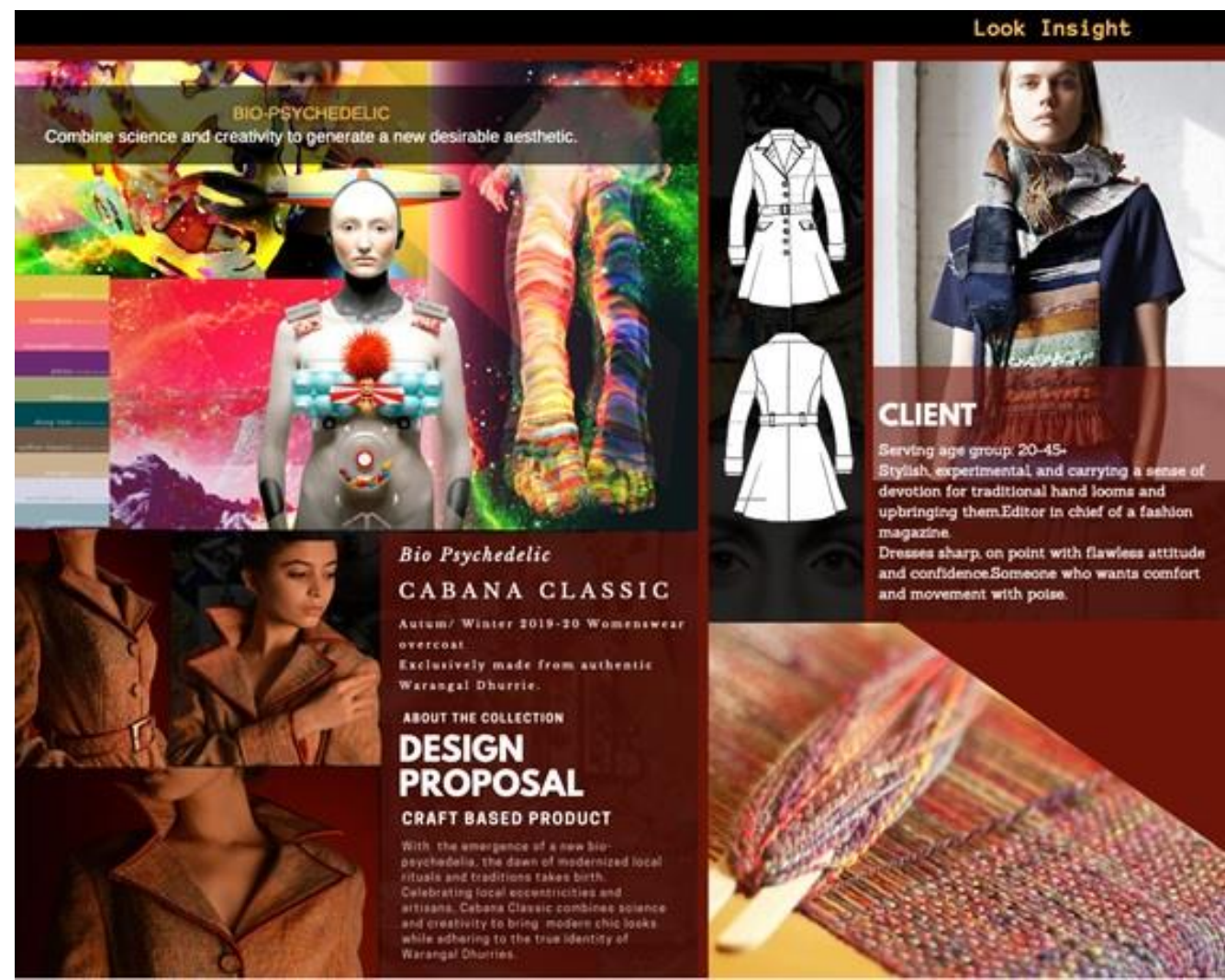

Picture 4: Design Exploration and Process by Mr. Faheem Siddiqui, Fashion Design 2019, NIFT Hyderabad.

\subsection{Exploration 2: (Picture 5)}

\subsubsection{Aim}

To contemporize the traditional stripe pattern of the Warangal dhurries and re-orient the fabric towards an apparel 
alternative

\subsubsection{Modifications Applied to Yarn}

The regular cotton warp of $6 / 20$ s count yarn was altered to $3 / 20$ s count. This ensured a reduction in the weight of the fabric and facilitated an improved drape that is suitable for outerwear apparel.

\subsubsection{Modifications Applied to Color}

A color scheme based on a theme-based concept was developed in accordance with the forecasted trends for A/W 2019-20

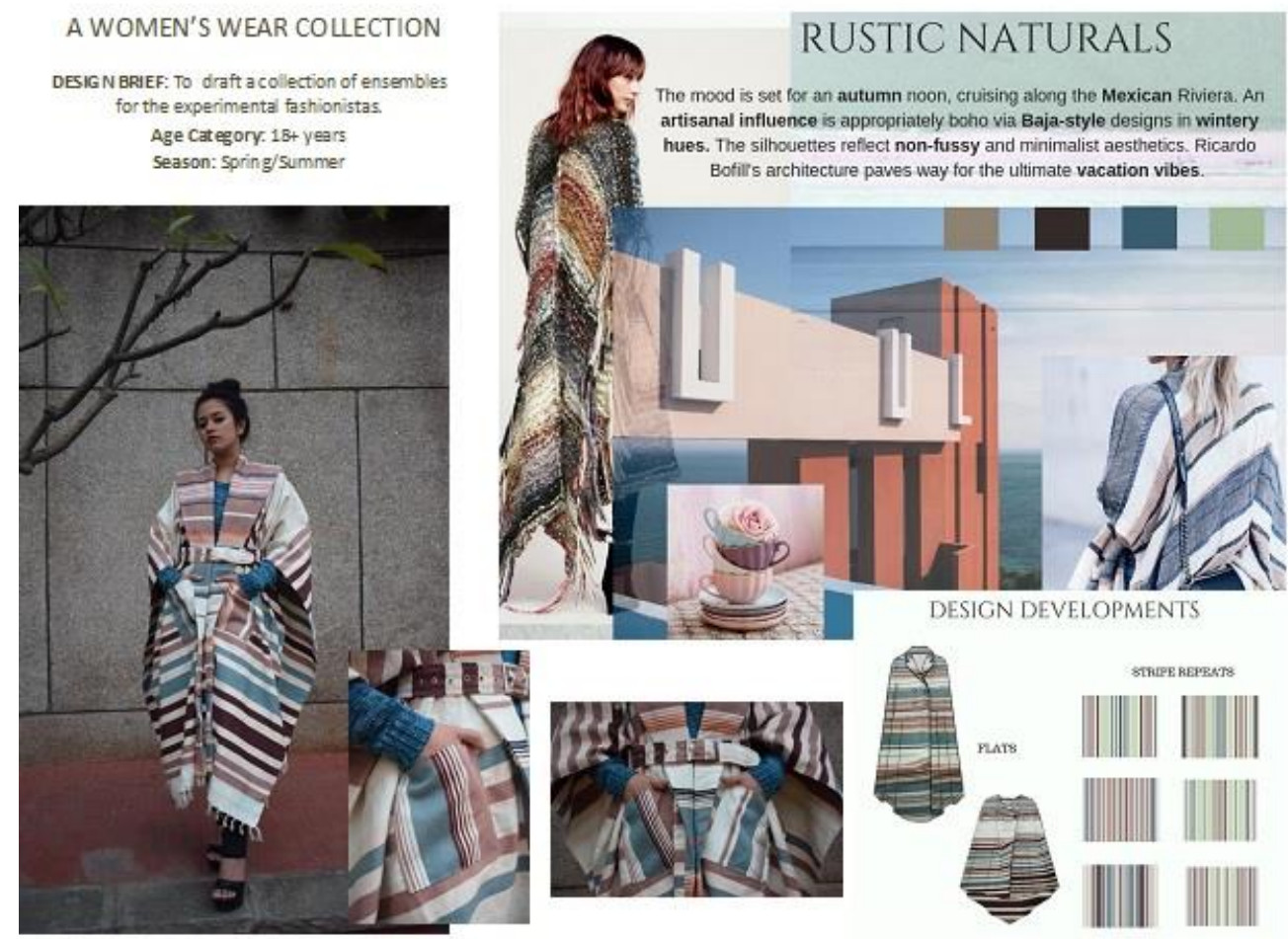

Picture 5: Design Exploration and Process by Ms. Ishita Tyagi, Fashion Design 2019, NIFT Hyderabad.

\subsection{Exploration 3. (Picture 6)}

\subsubsection{Aim}

To re-appropriate, the weave technique towards a street wear apparel line. Distressed Denim as an inspiration was considered for fabric exploration.

\subsubsection{Modifications Applied to Yarn}

The regular cotton warp of 6/20s count yarn was altered to 3/20s count. The fabric developed was similar to an 8-10 Oz Denim. A colored warp with white weft in plain weave was used to achieve the denim look. Surface treatments like discharge dyeing using domestic bleach in the concentration of 2:3 parts of bleach and water were applied to achieve the distressed washed denim look.

\subsubsection{Collection}

A collection of shackets (a hybrid of shirt and jacket) was developed suitable for a street wear look. 

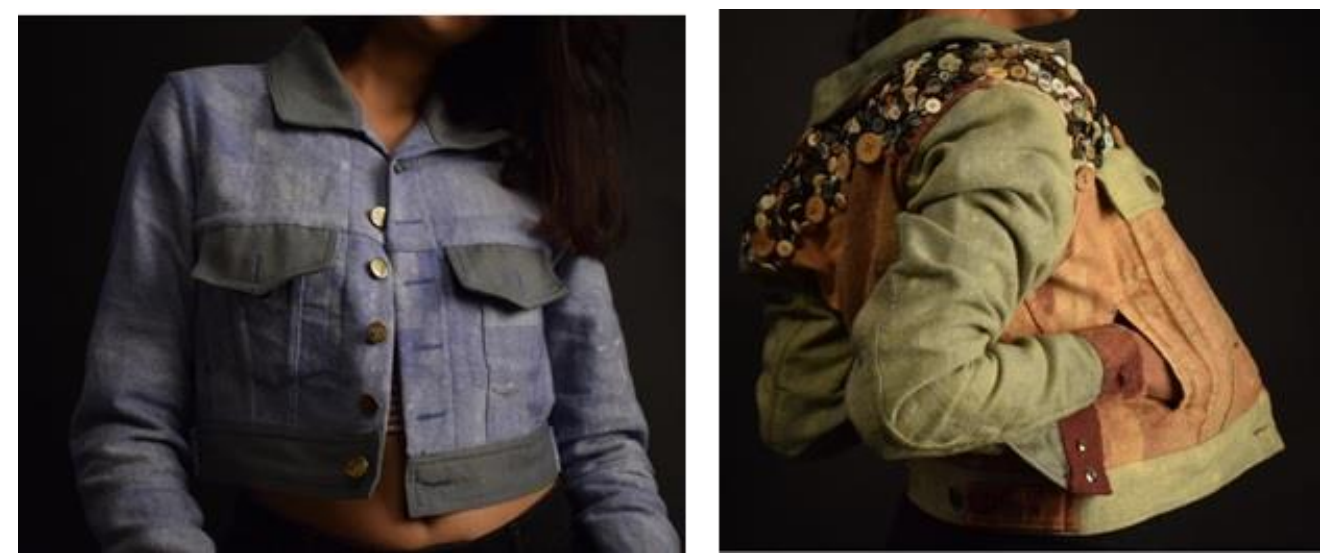

Picture 6: Design Exploration by Ms. Chetna Sinha, Fashion Design 2019, NIFT Hyderabad.

\section{DISCUSSIONS}

\subsection{Fashion Articulation}

Design intervention is a process that involves designing new products; redesigning existing products, with changes in shape, size, color, surface manipulations, function, and utility; exploring new markets and reviving lapsed markets; applying traditional skills to meet new opportunities and challenges; and the introduction of new materials, new processes, new tools and technologies (Kapur and Mittar, 2014). Local regional products are gaining recognition and are appreciated in urban and global markets as they are constantly evolving and innovating ways for survival and sustaining under severe constraints. There is tremendous scope for these regional product ideas and traditional knowledge skills to be developed for contemporary applications in India (Patel, 2010). To preserve tradition means to continuously develop it through the sustenance of skill and practice, to sustain skill and practice means to create better market orientation (Nugraha, 2010). The experimentation in this study attempts to renew the utilitarian aspect of the dhurrie and explore its application as an apparel fabric. This renewed application of the dhurrie towards an apparel weight adds diversified advancement of the craft skills, product range, and a handloom alternative to outer wear fabric range.

\subsection{Shifting Tradition to Enable Sustenance}

Indigenous traditions possess immense resilience towards adaptations. Thoughtful adaptations upholding the craft essence play a significant role in a progressive re-orientation of traditional skills. Shifting traditions to suit contemporary markets energizes the craft skills with new and expanded mediums. Transformation of floor covering into an apparel fabric explains the resilience of the skill without any deviation from the original process. Such design-based innovation can magnify the target of existing handloom skills as they are perceived as responsible alternatives for power loom fabrics.

As a link between the tradition and the craft, these weavers exist as carriers of traditional skills, if not for these carriers', traditions and its associated crafts cease to exist. The role of these weavers as carriers of skills is thus fundamental for the existence of Warangal dhurries today. While the limited and idled orientation of the product as floor coverings have sustained the craft skills at Warangal for a long, the added dimension of apparel orientation may surely stimulate market focus towards this skill of hand-weaving contributing towards beneficial sustenance of crafts skills.

\subsection{Apparel Alternative}

The cultural, social, and emotive language of Indian textile crafts is commonly articulated through technique, motifs, and 
color. Bright colors, geometric repetitive patterns, and interlocking zig-zag motifs have been the signature style of these dhurries. Once a product of high esteem the craft seemed to have slipped into a mundane existence. Such situations present a challenging picture for the continuance of the tradition by the next generation of weavers. The apparel sector with its wide range of products occupies a premium market spread. The wide variety of products in this segment demand fabrics of different weights. The design exploration in this study was hence based on the idea of orienting the existing weaving skills towards the development of a fabric that could be a contemporary to tweed, burlap or a denim, all of which have a significant contribution to the apparel market segment.

It is observed that the fabric developed by the weavers of Warangal in this exploration leant considerable resilience towards this transition. The re-orientation of colors as per the trend forecast is a key aspect that provided an additional dimension for enhancing the aesthetics in tune with the fashion consumption audience contributing to design appeal.

\section{CONCLUSIONS}

Modern mechanical or industrial skills have replaced indigenous craft skills in most sectors and more prevalently in the textile sector. Crafts cannot just be limited to perform the role of keeping the traditions alive, they can only be alive when they serve to earn a livelihood. The dynamic market trends, requirements, and profiles constantly demand for newness to generate interest in wider markets. Fashion perceived as an energetic enigma is a widely followed medium and holds textile crafts in close association. Fashion through fabric has been a discipline of academic, industrial, and economic interest. Association of crafts with fashion is mutually complementary as the former's indigenous traditional knowledge and cultural significance enhances the later through a legacy of rich narrative complimenting to the evolving dynamics of global fashion.

The exploration of diversifying the craft outcome from floor coverings to bottom weight apparel fabric can certainly augur better prospects as cotton as raw material, handloom as a technique and craft skills as cluster cumulatively complement each other towards a sustainable prospect in the apparel industry

\section{REFERENCES}

1. Chattopadhyay, K(1976). Carpet and floor coverings, The Glory of Indian Handicrafts, Clarion Borks, New Delhi, pp. 63-75

2. Internet - no author, Geographical Indication Application. (2015). Retrieved from https://www.origin-gi.com/i-gi-originworldwide-gi-compilation-uk/download/1174/14143/24.html

3. Internet - no author, Schemes for Handloom Weavers. (2013). Retrieved from http://pib.nic.in/newsite/PrintRelease.aspx? relid=98009

4. Jastesh (2002) Consumer Preferences for innovative articles made by Dhurries weaving techniques. M.Sc. thesis, Punjab Agricultural University, Ludhiana, India.

5. Levick, M., Crites, M., \& Nanji, A. (2008). India color: Spirit, tradition, and style. Chronicle Books: San Francisco, California, pp. $71-73$

6. Liebl, M, and Roy, T. (2004). "Handmade in India: Traditional craft skills in a changing world." In Poor People's Knowledge: Promoting Intellectual Property in Developing Countries, edited by Michael J Finger and Philip Schuler, 53-72. Washington DC: World Bank and Oxford University Press 
7. Mahendra, A. (2017, August 24). Warangal dhurries facing a slow death. Retrieved from https://www.thehansindia.com/posts/index/Telangana/2017-08-25/Warangal-dhurries-facing-a-slow-death/321655

8. Namrata, C. (2016). Warangal dhurrie project documentation book 2016 . Retrieved from https://issuu.com/namrata99/docs/warangal_dhurrie_project_-_document

9. Nanisetti, S. (2018, April 24). GI tag for Warangal dhurries brings hope to weavers. Retrieved from https://www.thehindu.com/news/cities/Hyderabad/gi-tag-for-warangal-dhurries-brings-hope-to-weavers/article23653731.ece

10. Niladri, BD., Rohit Kumar, S., Anand Pandey and Narayanan, B. G. (2018). The Existence of Carpet Industry in Bhadohi, India. Trends in Textile Engineering \& Fashion Technology, 3(3):1-10

11. Pradeep, KJ (2010) Indian handicrafts in globalization times: an analysis of global-local dynamics, Interdisciplinary Description of Complex Systems. 8(2):119-137

12. Punia P (2004) Village Dhurries of Hissar and Bihar: Present status and scope for change. Ph.D thesis, Delhi University, Delhi.

13. Ranjan, A., \& Ranjan, M. P. (2009). Handmade in India: A geographic encyclopedia of Indian handicrafts. New York: Abbeville Press.

14. Saini, P., Punia, P., Pruthi, $N$ and Singh, V (2014). Preferences of consumers for diversified use of Dhurrie material, International Journal of Textile and Fashion Technology. 4(2):1-6.

15. Shrilakshmi, B. and Padma, A. (2002). Study on Dhurries and carpets of Warangal, Textile Industry \& Trade J., 49-51.

16. Zeeshan, Heena Saudagar, and S. H. R. E. E. K. A. N. T. Sharma. "A production efficiency of input uses in the Indian carpet industry: Stochastic frontier approach." International Journal of Human Resource Management and Research 8.6 (2018): 11 22.

17. Devaraja, HM, S. Sugumar, and HR Arunkumar. "Study of Tensile Properties of Certain South Indian Wool and Wool Polyester Blended Yarns." International Journal of Textile and Fashion Technology (IJTFT) 7.5, Oct 2017, 49-56

18. Puspa, V. Singh, and P. Punia. "Consumer Acceptability for Diversified Durrie Products." International Journal of Applied and Natural Sciences (IJANS) 6 (2017): 41-44.

19. Bori, Geetashree, and M. Neog Rupjyoti. "Emerging Trends in Woven Textile Fabrics Designs of Tribal Mising Community in Assam." International Journal of Applied and Natural Sciences (IJANS) 6.5 (2017): 7-14. 
